\title{
Gold colitis induced by auranofin treatment of rheumatoid arthritis: case report and review of the literature
}

\author{
H E LANGER, G HARTMANN, G HEINEMANN, AND K RICHTER
}

From the Department of Internal Medicine, Division of Rheumatology, Hannover Medical School, FRG

SUMMARY A case of ulcerative colitis occurred during treatment of rheumatoid arthritis with the new oral gold preparation auranofin after a cumulative dose of $2160 \mathrm{mg}$. A barium enema showed loss of mucosal pattern and a rectal biopsy disclosed deep erosions, mucosal inflammation, and crypt abscesses. Precipitates of gold were seen in the periglandular stroma. On electron microscopy the gold deposits seemed to be identical to granules described in gold nephropathy. As the extrapolated serum gold level was within the normal range at the onset of the complication, the morphological findings suggested a local toxicity of the drug. The patient recovered within 14 days of withdrawal of auranofin and the start of therapy with sulphasalazine and steroids. A review of the published work shows that the previously reported mortality in gold colitis of $40 \%$ has decreased in recent years. The causes of this decrease may be both the earlier diagnosis of gold colitis and the improved intensive care of its severe complications.

Key words: ulcerative colitis, gold therapy-complications.

Gold salts are effective as slow acting antirheumatic drugs in rheumatoid arthritis, but treatment must be interrupted in $14-53 \%$ of the patients because of side effects. ${ }^{1-3}$ Drug colitis is known as a rare, but frequently fatal, complication of gold therapy. ${ }^{4}$ Since its introduction in $1976^{5}$ the new oral gold compound auranofin has proved its efficacy in rheumatoid arthritis. ${ }^{6-8}$ Side effects seem to be fewer and less severe than those seen with the intramuscular gold preparations. ${ }^{4}$ Two cases of gold colitis, however, have been observed during treatment with auranofin. ${ }^{9} 10$ We report a further case and discuss some aetiological, immunogenetic, and therapeutic aspects of this complication.

\section{Case report}

H I S T O R Y

A 47 year old man had suffered from erosive rheumatoid arthritis since 1979 . He had also

Accepted for publication 6 May 1987.

Correspondence to $\mathrm{Dr} \mathrm{H}$ E Langer, Abt für Krankheiten der Bewegungsorgane und des Stoffwechsels, Medizinische Hochschule Hannover, Konstanty-Gutschow-Strasse 8, D 3000, Hannover 61, Federal Republic of Germany. suffered intermittently from a duodenal ulcer for about 20 years. Otherwise he was well. In particular he did not have any indication of inflammatory bowel disease. Treatment of the rheumatoid arthritis with chloroquine was stopped after two years because of inefficacy. Subsequent gold therapy with aurothiopolypeptide was tolerated for two years without complications but then had to be stopped after a total dose of $1200 \mathrm{mg}$ because of dermatitis and eosinophilia in the peripheral blood $(8 \%)$. Treatment was changed to the oral gold preparation auranofin with $3 \mathrm{mg}$ twice daily for nine months, and later $3 \mathrm{mg}$ three times a day, without side effects. He also took $300 \mathrm{mg}$ ranitidine twice daily and $100 \mathrm{mg}$ diclofenac intramuscularly every second day. After 11 months and a total dose of $2160 \mathrm{mg}$ auranofin the patient suddenly developed mucous and bloody diarrhoea with six to seven stools a day, accompanied by abdominal pain and tenesmus.

CLINICAL EXAMINATION

Examination showed the typical joint deformities of rheumatoid arthritis. The abdomen was tender on palpation in the left lower quadrant. Otherwise no pathological findings were detectable. 


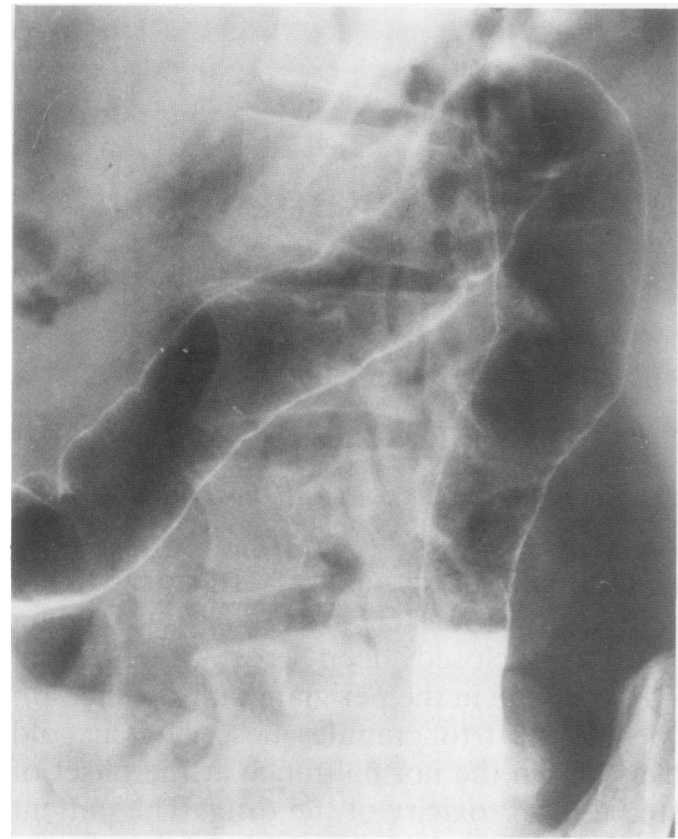

Fig. 1 Barium enema one week after the onset of bloody diarrhoea in gold colitis. Loss of mucosal pattern with irregular gut contours and absent haustration in the descending and transverse colon.

D I A G N OS TIC FIN DINGS

Laboratory investigations showed an eosinophilia of $9 \%$ in the peripheral blood but were otherwise normal. Rectosigmoidoscopy was performed after one week and showed intensive reddening and oedema of the mucosa with shallow ulceration and purulent deposits. A barium enema (Fig. 1) showed absent haustration in the descending and transverse colon with irregular gut contours. Histology of a rectal biopsy specimen showed erosions of the mucosa, a dense inflammatory infiltration of the lamina propria with polymorphonuclear neutrophil granulocytes, eosinophils, lymphocytes, plasma cells, and histiocytes (Fig. 2), and numerous cryptal abscesses (Fig. 3). Staining for gold showed punctate black precipitates immediately under the base of the glands and in the periglandular stroma (Fig. 4). Similar changes could not be observed in controls from five other patients with chronic inflammatory bowel disease. Electron microscopic investigation showed a number of phagocytotic cells within the mucosal stroma containing numerous lysosomal osmiophilic cytoplasmic structures (Fig. 5). Some inclusions were surrounded by a thin membrane, others lacked membranes and displayed

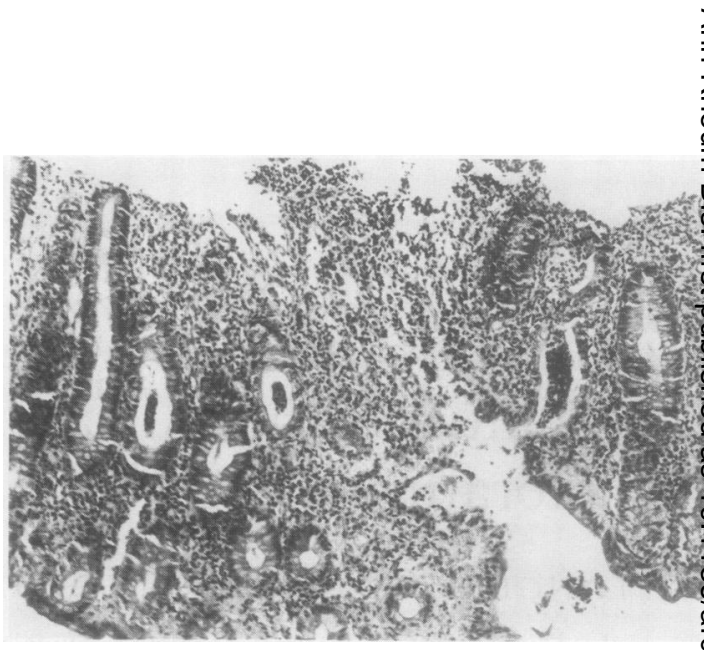

Fig. 2 Dense inflammatory infiltrate throughout the stromal layer of the rectal mucous membrane after therapy with auranofin three times a day. So called 'crypt abscesses' and ulcerative lesions as seen in ulcerative colitis.

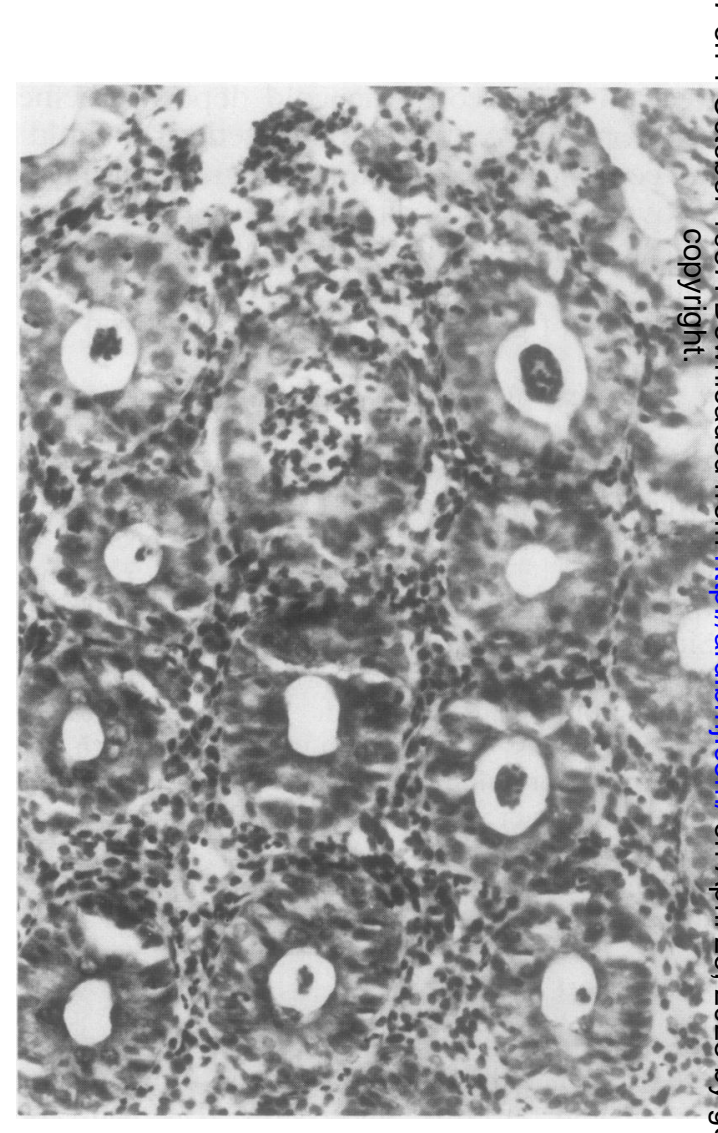

Fig. 3 Rectal mucous layer after therapy with $3 \mathrm{mg}$ auranofin three times a day. Severe lymphocytic, histiocytic, and polymorphonuclear leucocyte infiltration.

Numerous so called crypt abscesses. Loss of goblet cells. Glandular epithelium activated by inflammation. 


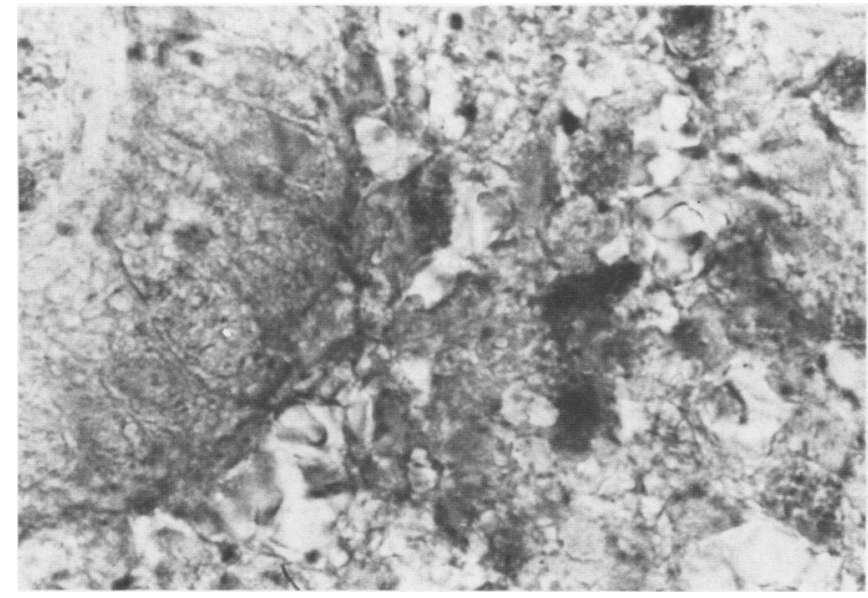

Fig. 4 Rectal mucous layer in auranofin induced colitis. Isolated and complex deposits of dark precipitations in macrophages within the interstitial tissue. Demonstration of gold according to Borchardt-Michaelis.

an indistinct periphery (Fig. 6). They measured from $10 \mathrm{~nm}$ to $32 \mathrm{~nm}$ in size and occurred at the bottom of the mucosal layer together with leucocytes and other non-specific inflammatory cells. These deposits seemed to be identical to granules described in gold nephropathy. The cells corresponded with those demonstrated histochemically (Fig. 4). We presume that these alterations are precipitations of metallic gold in the colonic mucosa due to the auranofin therapy. Serum gold levels were measured seven and eight weeks after the onset of symptoms and were $135 \mathrm{mg} / \mathrm{ml}$ and 130 $\mathrm{mg} / \mathrm{ml} \mathrm{respectively.} \mathrm{If} \mathrm{a} \mathrm{half} \mathrm{life} \mathrm{of} \mathrm{two} \mathrm{to} \mathrm{three}$ weeks is assumed, ${ }^{6}$ the serum gold level was within the therapeutic range at the onset of the complication. The HLA type was A2, A23, B27, Bw62, Cw2, Cw3, Dr4.

As HLA-B27 was positive a tomography of the sacroiliac joints was undertaken and showed normal joints.

\section{THERA PY AND COURSE}

Therapy with auranofin was stopped and treatment was begun with $1.5 \mathrm{~g}$ sulphasalazine four times a day and $50 \mathrm{mg}$ prednisone once daily. All symptoms disappeared after 14 days. A control rectosigmoidoscopy was performed after four weeks and showed normal findings. Steroids were reduced slowly and then withdrawn. In the follow up period of one year the patient showed no evidence of a relapse.

\section{Discussion}

It cannot be proved definitely that the observed colitis was due to auranofin, but the absence of symptoms of colitis in the past and the rapid

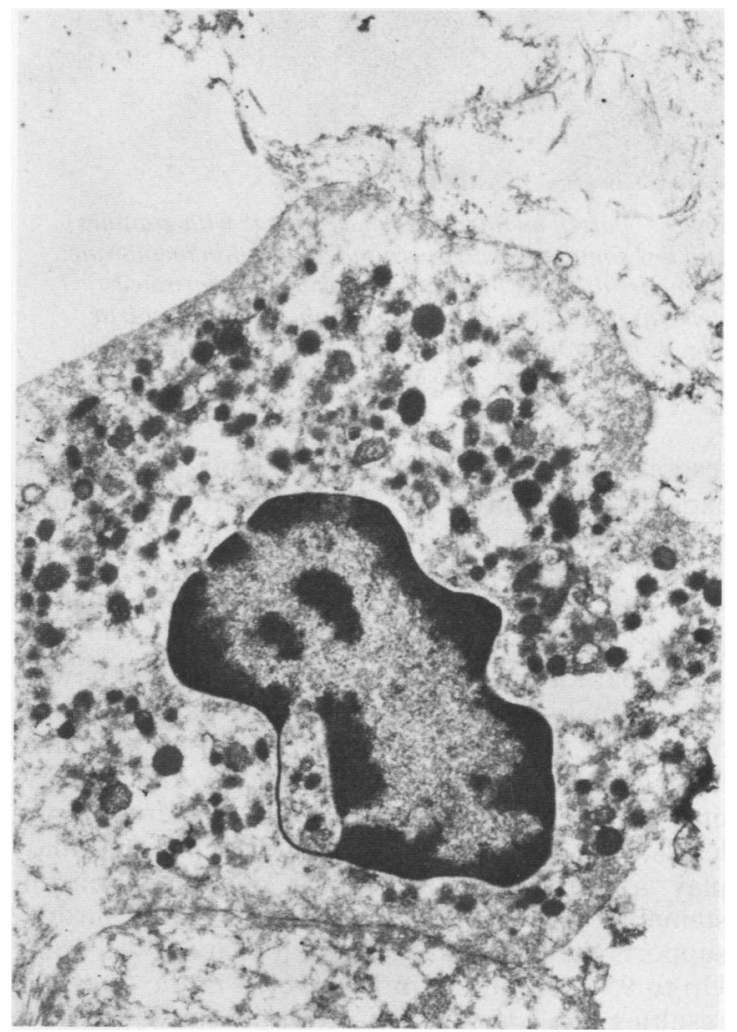

Fig. 5 Macrophagic interstitial cell in the rectal mucous membrane in gold colitis. Numerous lysosomal and granular structures in the cytoplasma. Location is the same as that shown in Fig. 3. Electron microscopy was carried out after initial formol fixation and conventional paraffin technique. 


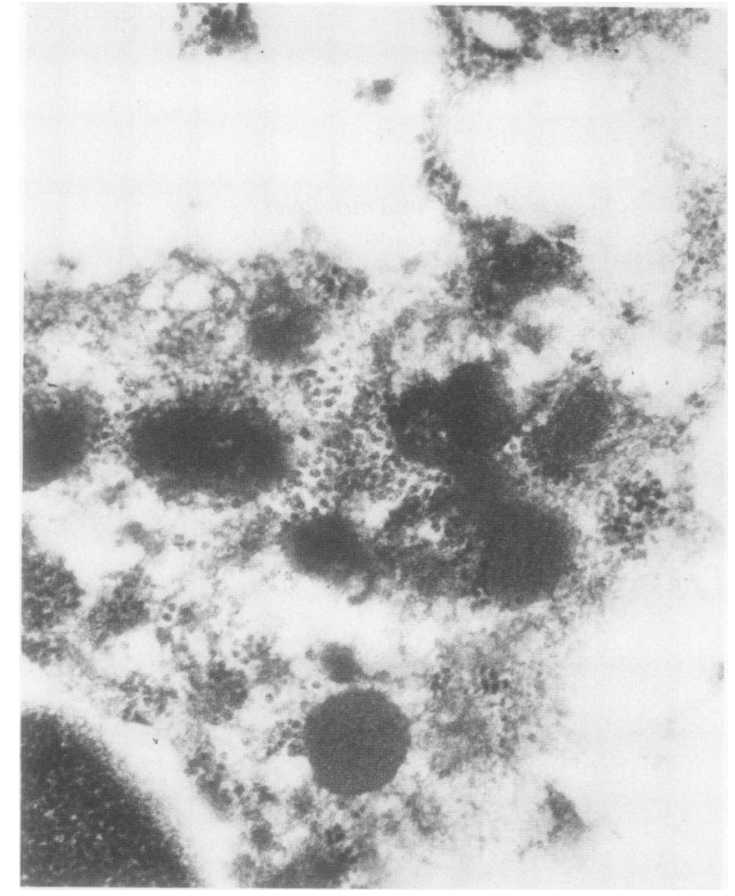

Fig. 6 Part of an interstitial macrophage with granules and lysosomes partially surrounded by a thin membrane. Compare this with the histochemically demonstrated deposits in Fig. 3 and the electron photomicrograph in Fig. 4. Electron microscopy was carried out after initial formol fixation and conventional paraffin technique.

response after withdrawal of the drug make other explanations improbable. Furthermore, the patient had not taken other drugs known to cause colitis. ${ }^{13}$ Twenty eight cases of gold induced colitis have been reported, including two cases due to auranofin ${ }^{14-35}$ (Tables 1 and 2).

The pathogenesis of the complication is unknown. The normal serum gold level in the patient makes overdosing of auranofin as the cause of colitis unlikely. It is known that the efficacy and toxicity of gold therapy are not related to serum gold levels, ${ }^{36-38}$ suggesting that local mechanisms may play a part. The histological demonstration of stainable gold in the colonic mucosa further supports the possibility of local toxicity of the drug. Up to $95 \%$ of auranofin is excreted in the faeces, ${ }^{39}$ resulting in a constant contact of the substance with the colonic mucosa. Diarrhoea frequently occurs in auranofin therapy, ${ }^{40} 41$ probably caused by a reversible defect in intestinal permeability. ${ }^{42}$ Analogously to mechanisms for gold nephritis ${ }^{11} 124344$ it is suggested that in predisposed individuals the constant exposure of the colonic

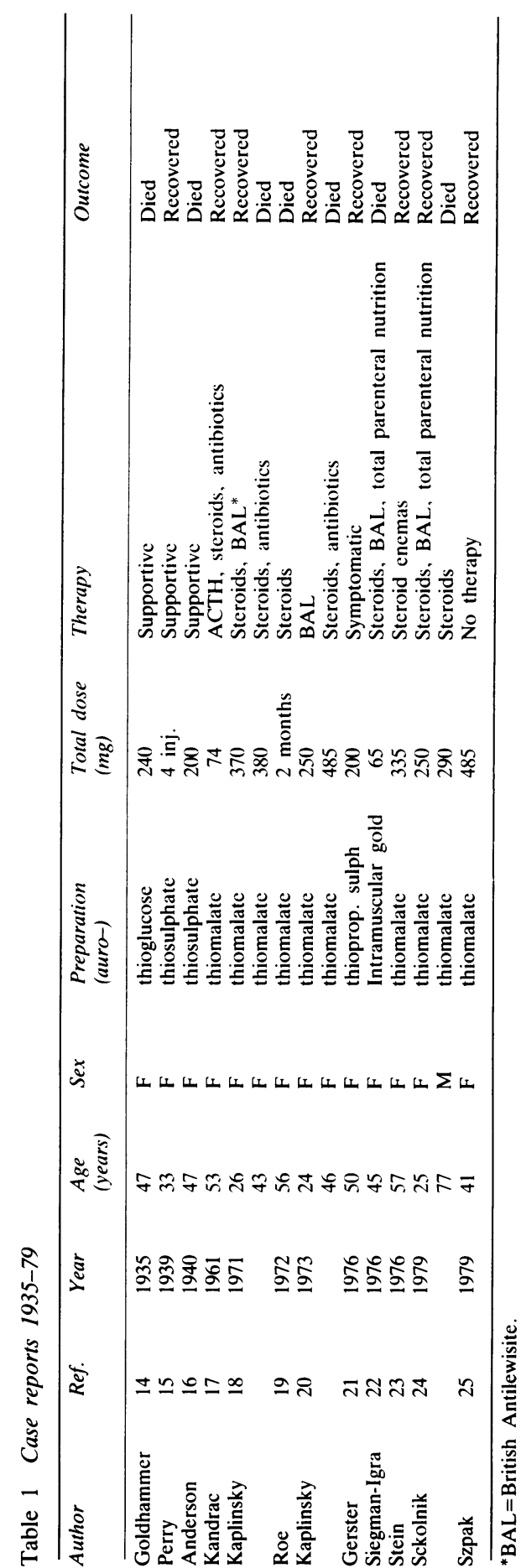




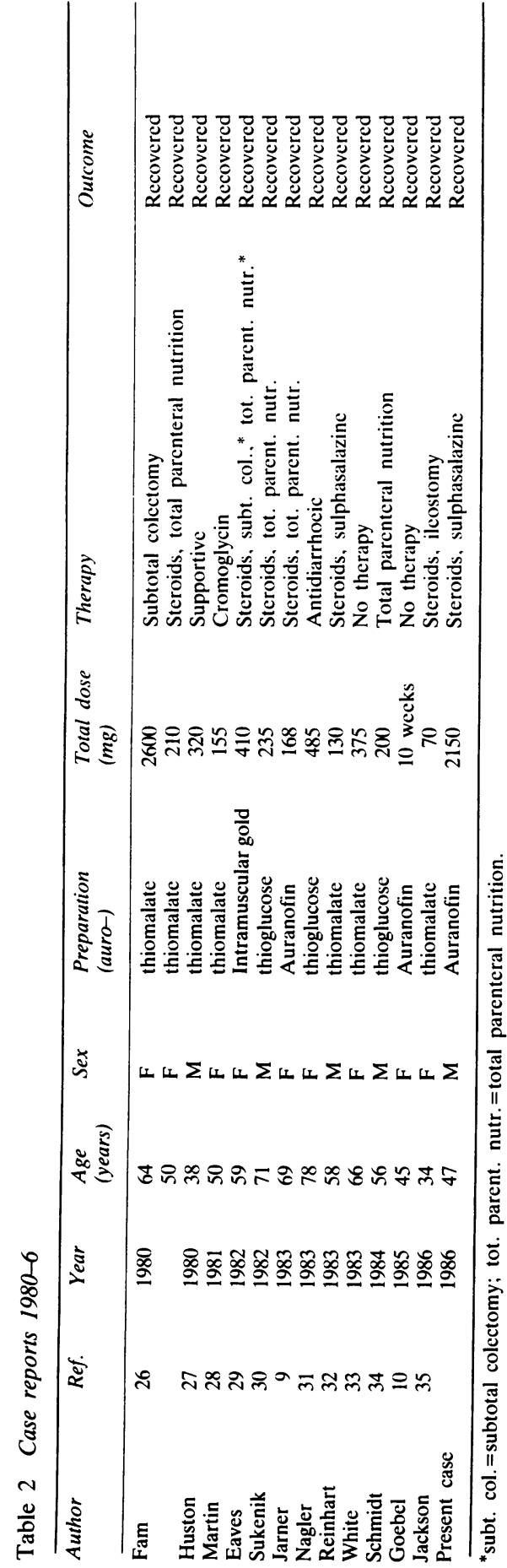

epithelia to the excreted gold may lead to a change in their antigenicity with formation of antibodies against the mucosa and development of ulcerative colitis. Unfortunately investigations of immune complexes were not performed in the rectal biopsy of our patient.

The complication was not associated with HLA-Dr3, the incidence of which is increased in patients with adverse reactions to gold, in particular proteinuria. ${ }^{45-47}$

Diagnosis may be made by rectosigmoidoscopy with rectal biopsy or by barium enema. A review of the published work shows that the former methods seem to be most effective in diagnosing gold colitis. In the reported cases rectal biopsies were performed 15 times and led to the diagnosis in all cases, ${ }^{9}$ 20-24 26-29 $32-34$ while rectosigmoidoscopy showed the typical picture of ulcerative colitis in seven $^{9} 20232526.32 .34$ and slight alterations in five 21222933 of 16 cases. The biopsy specimens were normal in four patients. ${ }^{2+28} 31$ Barium enema was negative in $\operatorname{six}^{22-24} 282931$ and positive in five patients. ${ }^{9} 2026$

After withdrawal of the drug and introduction of sulphasalazine and steroids the symptoms disappeared within two weeks. Other authors have tried several therapeutic regimens, including steroids, British Antilewisite (BAL), sodium cromoglycate, total parenteral nutrition, and colectomy with mixed results (Table 1). In our view the treatment of choice is sulphasalazine as this drug is also effective in rheumatoid arthritis. Some patients remitted spontaneously without further therapy after withdrawal of gold. ${ }^{10} 2533$ Because of lethal infectious complications due to severe protein losses under the longlasting diarrhoea with hypogammaglobulinaemia and an additional steroid therapy ${ }^{202}$ steroids should be used cautiously.

Stein and Urowitz ${ }^{23}$ in a review article on drug induced colitis ${ }^{13}$ quote a mortality from gold colitis of $40 \%$. The analysis of reported cases shows, however, that among 14 patients since 1980 none have died of this complication (Table 2). The improved prognosis may be a result of earlier diagnosis and improved supportive therapy, particularly total parenteral nutrition. All patients receiving auranofin recovered, though one patient developed toxic megacolon. ${ }^{9}$ Despite the improved outcome in recent years gold colitis should be regarded as a potentially lethal complication. Consequently, diarrhoea during gold therapy should always be taken seriously and early investigation by rectosigmoidoscopy with rectal biopsy should be undertaken in all suspicious cases.

We are grateful to Dr P Cullen for help in the correction of the manuscript. 


\section{References}

1 The Research Subcommittec of the Empire Rheumatism Council. Gold therapy in rheumatoid arthritis: report of a multicentre controlled trial. Ann Rheum Dis 1960: 19: 95-119.

2 The Cooperating Clinics Committee of the American Rheumatism Association. A controlled trial of gold salt therapy in rheumatoid arthritis. Arthritis Rheum 1973: 16: 353-8.

3 Grindulis K A. Mcconkey B. Outcome of attempts to treat rheumatoid arthritis with gold. penicillamine. sulphasalazine. or dapsone. Ann Rheum Dis 1984: 43: 398-401.

4 Gottlicb N L. Gold compounds in the rheumatic diseases. In: Kelley W N. Harris E D. Ruddy S. Sledge C B. eds. Textbook of rheumatology: Philadelphia: Saunders, 1981: 796-814.

5 Finkelstein A E. Walz D T. Batista V. Mizraji M. Roisman F, Misher A. Auranofin-new oral gold compound for treatment of rheumatoid arthritis. Ann Rheum Dis 1976: 35: 251-7.

6 Berglöf F. Berglöf K. Walz D T. Auranofin: an oral chrysotherapeutic agent for the treatment of rheumatoid arthritis. $J$ Rheumatol 1978: 5: 68-74.

7 Schattenkirchner M. Kaik B. Mueller-Fassbender H. Rau R, Zeidler H. Auranofin and sodium aurothiomalate in the treatment of rheumatoid arthritis. a double-blind, comparative. multicenter study. J Rheumatol /Suppl/ 1982: 9: 1849.

8 Ward J R. Williams H J. Egger M J, et al. Comparison of auranofin, gold sodium thiomalate, and placebo in the treatment of rheumatoid arthritis. Arthritis Rheum 1983: 26: 13)315.

9 Jarner D. Nielsen A M. Auranofin (SK+F 39162) induced enterocolitis in rheumatoid arthritis. Scand J Rheumatol 1983: 12: 254-6.

10) Goebel K M. Storck U. Kohl F V. Hausmann L. Klinischer Effekt und unerwünschte Arzneimittelwirkungen von Auranofin hei rheumatoider Arthritis. Innere Medizin 1985: 12: 39-45.

11 Silberberg D S. Kidd E D. Shmitka T K. Ulan R A. Gold nephropathy. A clinical and pathologic study. Arthritis Rheum 1970): 13: 812-25.

12 Katz A. Little A H. Gold nephropathy. An immunopathologic study. Archives of Pathology 1973: 96: 133-6.

13 Fortson W C. Tedesco F J. Drug-induced colitis: a review. Am J Gastroenterol 1984: 79: 878-83.

14 Goldhammer $\mathrm{S}$. Ein Fall von tödlicher Solganolvergiftung. Med Klinik 1935; 31: 645-7.

15 Perry M W. Gold injections and colitis. JAMA 1939: 113: 965.

16 Anderson N L. Palmer W L. The danger of gold salt therapy. Report of a fatal case. JAMA 1940: 115: 1627-30.

17 Kandrac M. Pav J. Pechova I. Successful steroid therapy of severe enteritis caused by gold therapy. Cas Lek Cesk 1961; 100: $361-7$.

18 Kaplinsky N. Pras M. Ulcerative colitis with gold treatment in rheumatoid arthritis (Hebrew). Harefuah 1971: 80: 406-7.

19 Roc M. Sears A D. Arndt J H. Gold reaction panenteritis. Radiology 1972; 104: 59-60)

20) Kaplinsky N. Pras M. Frankl O. Severe enterocolitis complicating chrysotherapy. Ann Rheum Dis 1973: 32: 574-7.

21 Gerster J C, De Kalbermatten A, De Peyer R. Toussaint M. Carrel J. Réactions toxiques aux sels d'or avec entérocolite grave chez un homme atteint d'une polyarthrite rhumatoide Schweiz Med Wochenschr 1976; 106: 1606-8.

22 Siegman-Igra Y, Yaron M. Siletzki M. Schujman E. Gilat T. Colitis and death following gold therapy. Rheumatol Rehabil 1976; 15: 245-7.

23 Stein H B. Urowitz M B. Gold-induced enterocolitis. Case report and literature review. J Rheumatol 1976; 3: 21-6.

24 Sckolnik B R. Katz L A, Kozower M. Life-threatening enterocolitis after gold salt therapy. J Clin Gastroenterol 1979; 1: $145-8$.

25 Szpak M W, Johnson R C, Brady C E. Boswell R N. Gold (Au) induced enterocolitis [Abstract|. Gastroenterology 1979; 76: 1257.
26 Fam A G, Paton T W. Shamess J. Lewis A J. Fulminant colitis complicating gold therapy. J Rheumatol 1980; 7: 479-85.

27 Huston G J. Gold colitis, therapy and confirmation of mucosaly? recovery by measurement of rectal potential difference Postgrad Med J 1980): 56: 875-6.

28 Martin D M. Goldman J A. Gilliam J. Nasrallah M. Gold induced eosinophilic enterocolitis: response to oral cromolyne sodium. Gastroenterology 1981: 80: 1567-70.

29 Eaves R. Hansky J. Wallis P. Gold induced enterocolitis: case report and a review of the literature. Aust NZ J Med 1982: 12요 $617-20$.

30) Sukenik S. Hirsch M. Yanai-Inbar I. Krawiec Freund B Horowitz Y. Enterocolitis complicating chrysotherapy. Cas report and review of the literature. Isr J Med Sci 1982: 18: 104()$-3$

31 Nagler J. Paget S A. Nonexudative diarrhea after gold salw therapy: case report and review of the literature. $A m$ h Gastroenterol 1983: 78: 12-14.

32 Reinhart W H. Kappeler M. Halter F. Severe pseudomem: branous and ulcerative colitis during gold therapv. Endoscop 1983: 15: 70-2

33 White R F. Major ( A C. Gold colitis. Med J Aust 1983; 1 $174-5$

34 Schmidt H, Rcimann J F. Schmid A. et al. Gold-Kolitis. Dtsch Med Wochenschr 1984: 109: 1583-5.

35 Jackson C W. Habonbi N Y. Whorwell P J. Schofield P F. Gold induced enterocolitis. Gut 1986: 27: 452-6.

36 Mascarenhas B R. Granda J L. Freyberg R H. Gold metao bolism in patients with rheumatoid arthritis treated with gol$\Phi$

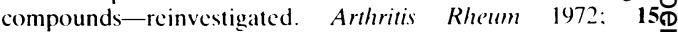
391-4(1)2.

37 Gottlicb N L. Smith P M. Smith E M. Pharmacodynamic ${ }^{197} \mathrm{Au}$ and ${ }^{145} \mathrm{Au}$ labelled aurothiomalate in blood: correlinom with course of rheumatoid arthritis, gold toxicity and excretion. Arthritis Rheum 1974: 17: 171-81.

38 Dahl S L. Coleman M L. Williams H J. et al. Lack of correlatith between blood gold concentrations and clinical response ip patients with definite or classic rheumatoid arthritis recciving auranofin or gold sodium thiomalate. Arthritis Rheum 1985: 28\% $1211-8$.

39 Gottlieb N L. Comparative pharmacokinetics of parenteral an oral gold compounds. J Rheumatol [Suppl] 1982: 9: 99-109윽

40) van Riel P L C M. Gribnan F W J, van de Pritte L B A? Tap S H. Loose stools during auranofin treatment: clinical stud? and some pathogenetic possibilities. $J$ Rheumatol 1983; 10.9. 222-6.

41 Bandilla K. Gross D. Gross W, et al. Oral gold therapy wit auranofin. J Rheumatol |Suppll: 1982: 9: 154-9.

42 Behrens R. Devereaux M. Hazleman B. Szaz K. Calvin Neale G. Investigation of auranofin-induced diaırhoea. GiJ 1986: 27: 59-65

43 Watanabe I. Whittier C. Moore J. Cuppage F E. Gold nephro pathy. Ultrastructural. fluorescence, and microanalytic studiog of two patients. Arch Pathol Lab Med 1976: 100: 632-5.

44 Viol G W. Minielly J A. Bistricki T. Gold nephropathy. Tissum analysis by $x$ ray fluorescent spectroscopy. Arch Pathol La Med 1977: 101: 635-40.

45 Wooley P H. Griffin J. Panayi G S. Batchelor J R. Welsh K F Gibson T J. HLA-Dr antigens and toxic reaction to aurothiomalate and D-penicillamine in patients with rheumatoif arthritis. N Engl J Med 1980; 303: 300-2.

46 Perrier $P$. Raffoux C. Thomas P. et al. HLA antigens and toxi reactions to sodium aurothiopropanol sulphonate and $\widehat{D}$ penicillamine in patients with rheumatoid arthritis. Ann Rheu Dis 1985; 44: 621-4.

47 Hakala M, van Assendelft A H W, Ilonen J. Jalava of Tiilikainen A. Association of different HLA antigens witto various toxic effects of gold salts in rheumatoid arthritis. Am Rheum Dis 1986; 45: 177-82. 